\title{
Rainfall amount determines annual herb controls over soil seed bank and its similarity with vegetation in the Tengger Desert
}

\author{
Ya-Fei Shi ${ }^{1,2}$, Zeng-Ru Wang ${ }^{3}$, Bing-Xin Xu ${ }^{1,2}$, Jian-Qiang Huo ${ }^{1,2}$, Rui Hu' ${ }^{1}$, Yang Zhao ${ }^{1^{*}}$ and Zhi-Shan Zhang ${ }^{1^{*}}$ (D)
}

\begin{abstract}
Background: Soil seed banks may offer great potential for maintaining and restoring desert ecosystems that have been degraded by climate change and anthropogenic disturbance. However, few studies have explored the yearto-year dynamics in the species composition (richness and abundance) of these desert soil seed banks. Thus, we conducted a 4-year study to assess the effects of environmental factors (meteorology and microtopography) and aboveground vegetation on the soil seed bank of the Tengger Desert, China.

Results: We found the seed bank was dominated by annual herb species both in species richness and abundance. More rainfall in the growing season increased the number of seeds in the soil seed bank, and quadrat micro-elevation had a negative effect on soil seed bank size. The species composition in the seed bank had significantly larger between-year similarity than that in the aboveground vegetation due to the dominance of annual herb species. For different life forms, the species composition of annual herbs showed distinctly larger temporal similarity between the aboveground vegetation and the seed bank compared with perennial herbs and shrubs.

Conclusions: Our findings highlight that the combined effects of environmental factors and plant life forms determine the species composition (especially the abundance) of soil seed banks in deserts. However, if degraded desert ecosystems are left to regenerate naturally, the lack of shrub and perennial herb seeds could crucially limit their restoration. Human intervention and management may have to be applied to enhance the seed abundance of perennial lifeforms in degraded deserts.
\end{abstract}

Keywords: Desert ecosystem, Seed bank dynamics, Rainfall, Plant type, Vegetation regeneration, Annual herbs

\section{Introduction}

Desert ecosystems, limited by water and nutrients, are well known for their sparse vegetation and ecological vulnerability (Houerou 1996; Maestre et al. 2012). Anthropogenic disturbance (e.g., heavy livestock grazing and mining) and climate change (e.g., warming, increases in drought frequency and duration, and altered precipitation regimes) profoundly affect the composition,

\footnotetext{
*Correspondence: zhaoyang66@126.com; zszhang@lzb.ac.cn

1 Shapotou Desert Research and Experiment Station, Northwest Institute of Eco-Environment and Resources, Chinese Academy of Sciences,

Lanzhou 730000, Gansu Province, People's Republic of China

Full list of author information is available at the end of the article
}

structure, and functioning of desert ecosystems (Bai et al. 2020; Li et al. 2018; Reynolds et al. 2007; Sommer et al. 2011). Seeds accumulated in soil seed banks contribute towards the persistence of plant species in communities undergoing environmental change and disturbance, for example accelerating the vegetation regeneration under the background of habitat isolation and climate change (Estrada et al. 2015; Stocklin and Fischer 1999), and promoting demographic recovery after a drought spell (LaForgia et al. 2018). Soil seed bank sustains the diversity of native species, provides a source for regeneration of vegetation after disturbance, and also increases the resistance of plant communities to invasive alien species (Arruda et al. 2018; Bakker et al. 1996; Ma et al. 2019). 
Therefore, understanding the composition (richness and abundance) and dynamics of soil seed banks is an important issue for the degraded ecosystem restoration (Huang et al. 2018; Montiel and Montaña 2003; Nano et al. 2013). However, compared with aboveground vegetation, our understanding of soil seed banks in desert areas is lacking (Snyman 2013).

The composition of seed banks is generally determined by local environmental conditions and seed dispersion of aboveground vegetation (Jaganathan et al. 2015). Two main environmental factors were categorized that significantly influence the seed bank in desert areas (Bakker et al. 1996; Montiel and Montaña 2003). First, meteorological factors, such as rainfall in the growing season, can determine the growth and reproduction of aboveground vegetation, and thus affect seed yields (Royo and Ristau 2013). Furthermore, rainfall events also affect soil water content and cause heterogeneity in soil surface, which could further influence seeds upon entering the soil (Hu et al. 2019). Prevalent wind contribute to variation in seed dispersal because most desert taxa are anemochorous (Ozinga et al. 2004; Tackenberg and Stöcklin 2008). Second, microtopographic conditions, such as micro-elevation and micro-slope, not only determine seed yields indirectly through driving the distribution of the aboveground vegetation (Gomaa 2014), but also cause soil microtopographic and photothermal differences which might have further impact on seed input and germination (Boudell et al. 2002; Qian et al. 2016). However, the relative effects of these environmental factors on the species richness and size of desert soil seed banks is unknown, hampering our ability to comprehensively assess the dynamics of desert soil seed banks.

Beyond the environmental conditions, aboveground vegetation composition directly affects soil seed banks (Bakker and Berendse 1999; Brändel and Schütz 2005). As the extreme environmental conditions in deserts, the different plant life forms and their variety of reproductive strategies may play a key role in the species richness and abundance of the soil seed bank. For example, some shrub species and perennial herb species that depend on a combination of vegetative and seed reproduction methods tend to occur less frequently and thus have lower relative abundance in the seed bank (Ma et al. 2002). However, patches of soil under shrubs could accumulate larger seed banks because many wind-dispersed seeds may be trapped by the clumped vegetation (Aguiar and Sala 1997). More importantly, differences in soil microhabitats caused by shrubs may affect seed germination and persistence (Sternberg and Yu 2004). Alternatively, many annual herbs opportunistically produce a large number of seeds in their short and erratic growing season (Bakker et al. 1996). Because of this high seed production, annual herbs tend to contribute more to soil seed banks than other life forms.

As climate change and anthropogenic disturbance affect terrestrial ecosystems (Houerou 1996), ecologists have made great efforts to explore the role of soil seed banks in maintaining ecological stability and reconstructing degraded ecosystems (Chang et al. 2001; Jacquemyn et al. 2011; Kalamees et al. 2013). It seems likely that the species composition of soil seed banks fluctuates less than aboveground vegetation which thus may suggest great potential in the ability of soil seed banks to reconstruct and restore degraded desert ecosystems. In other words, the temporal similarity of species composition within seed bank is larger than the aboveground vegetation community (Kalamees et al. 2013; Ma et al. 2017). However, due to the great superiority of dominant species of which differed with other biomes, the temporal dynamics of soil seed bank and the similarity between the above- and below-ground groups is unclear.

In this study, we conducted a 4-year continuous study in a typical desert ecosystem to determine how environmental factors and aboveground vegetation affect the composition of the soil seed bank. We hypothesized that (1) environmental factors, especially rainfall, directly and indirectly affect the seed bank through their effects on the growth of aboveground vegetation; (2) the seeds of annual herb species dominate in driving changes in the size of the seed bank because of their unique reproductive strategy; and (3) due to the combined effects of environmental factors and aboveground vegetation, between-year changes in soil seed bank would be less pronounced than that of vegetation, i.e., the similarity within the seed bank is larger than that within the aboveground vegetation.

\section{Materials and methods \\ Study site}

The study site, Hongwei, was located on the southeast edge of the Tengger Desert in northwestern China $\left(37^{\circ} 27^{\prime} \mathrm{N}, 104^{\circ} 46^{\prime} \mathrm{E}\right.$, elevation: $1570 \mathrm{~m}$ a.s.l.). This area is a transitional zone from sandy desert to steppe (Additional file 1: Fig. S1a and b), with an 8-month growing season from April to October (Chen et al. 2018). The mean annual temperature is about $9.6{ }^{\circ} \mathrm{C}$, ranging from $-25.1^{\circ} \mathrm{C}$ in January to $38.1{ }^{\circ} \mathrm{C}$ in July. The mean annual precipitation is about $186 \mathrm{~mm}$, with most occurring from June to September. The annual potential evaporation is as high as $2900 \mathrm{~mm}$. The mean annual wind velocity is $2.9 \mathrm{~m} \mathrm{~s}^{-1}$, and dust events are recorded 122 days per year, on average. The soil type in this area is aeolian sandy soil (FAO/UNESCO 1974), characterized by a covering of biological soil crusts and low soil organic matter and nutrient content (Chen et al. 2018). The predominant 
plant groups are shrubs, annual herbs, and perennial herbs (Additional file 1: Tables S1 and S2).

\section{Seed bank sampling and seedling emergence experiment} At the study site, a $148 \mathrm{~m} \times 4 \mathrm{~m}$ transect along the windward/leeward transect was established and divided into 37 quadrats of $4 \mathrm{~m} \times 4 \mathrm{~m}$. To examine species richness and abundance in the soil seed bank, we collected soil samples in early March from 2012 to 2015. At that time, the seeds have not yet germinated, but also no new seeds have been produced. Thus, the seed bank can be regarded as representative of the previous year after seed production and input. In each quadrat, five cylindrical soil cores (7 $\mathrm{cm}$ in diameter and $5 \mathrm{~cm}$ in depth) were taken, placed in a quincunx, and mixed into a composite sample (Additional file 1: Fig. S1c) ( $n=37$ composites for each year). To avoid repeated sampling at the same location, the soil core locations were marked after each sampling, and thus the next year's sampling could be taken $10 \mathrm{~cm}$ away in the same direction. The soil samples were packaged and transported to Shapotou Desert Research and Experiment Station (SDRES) of the Chinese Academy of Sciences, and sieved through a $6 \mathrm{~mm}$ mesh to remove plant fragments, coarse debris, and stones.

The seedling emergence method was used to determine the species richness and abundance of the germinable seed bank (Chang et al. 2001; Wolters and Bakker 2002). First, 37 plastic pots $(30 \mathrm{~cm}$ in diameter and $30 \mathrm{~cm}$ in depth) with drainage holes in the bottom were filled to $20 \mathrm{~cm}$ depth with sandy soil collected from the moving sand dunes. The soil was oven-dried at $150{ }^{\circ} \mathrm{C}$ for $4 \mathrm{~h}$ to kill any living seeds. Then, the soil samples were distributed evenly on the sandy surface of each pot to about $1 \mathrm{~cm}$ depth (Ma et al. 2017). The pots were covered with a light-transmitting plastic net to catch any incoming seeds and were watered every day. The pots were inspected weekly for any emerging seedlings. Once they could be identified, seedlings were removed to keep densities low. Unknown seedlings were transplanted to separate plots and grown until identification was possible. The germination experiment continued for 7 months, and the monitoring ceased when no more seedlings emerged for two consecutive weeks. The soil was then sifted and inspected carefully for any remaining seeds.

\section{Measurement of aboveground vegetation and environmental factors}

To measure the aboveground vegetation, surveys were conducted every September from 2011 to 2014. All species encountered in the aboveground vegetation and in the soil seed bank were classified by three life forms (shrubs, perennial herbs, or annual herbs; Additional file 1: Tables S1 and S2). Species were identified and categorized into life form categories for both aboveground vegetation and seed bank species according to the species description for the Flora of Desert in China (Liu et al. 1985). The richness, abundance, and coverage of shrubs were determined for each large quadrat $(4 \mathrm{~m} \times 4 \mathrm{~m})$. The presence, abundance, and coverage of herbs were measured in four $0.5 \mathrm{~m} \times 0.5 \mathrm{~m}$ quadrats (Additional file 1: Fig. S1c) placed at 1-m intervals in every large quadrat.

Environmental factors including meteorological conditions and microtopographic variables of quadrats were measured. A micro-weather station (HOBO U30 weather stations, Onset Computers, Bourne, MA, USA) was established in 2009 about $500 \mathrm{~m}$ from the study site to collect half-hourly data on rainfall, air temperature and humidity, solar radiation, and wind direction and velocity. Soil water content in the topsoil along the transect was measured using a neutron probe (CNC503DR, Beijing Nucleon Instrument Company, Beijing, China) twice monthly during the growing season (April-October) and once monthly during the non-growing season (November to March). For the microtopographic factors, the micro-elevation, slope gradient and slope aspect of each $4 \mathrm{~m} \times 4 \mathrm{~m}$ quadrat were calculated in 2009 after measuring the coordinates using a high-precision real-time kinematic instrument (S86, South, Guangzhou, China).

\section{Data analysis}

Structural equation modeling (SEM) were used to test our hypothesis that how the environmental factors (i.e., meteorology during the measured years and microtopography of quadrats) and the aboveground vegetation characteristics affect the species richness and abundance of the seed bank in a direct and indirect way. Initial concept models were first constructed before analysis (Additional file 1: Fig. S2). Because of the difference in the temporal and spatial scales of meteorological factors and microtopographic factors in our study, we constructed one SEM for each. The vegetation variables included species richness and abundance of the aboveground vegetation.

As the main meteorological factors, rainfall, soil water content and wind velocity in the growing season (AprilOctober) were considered in our analysis. Because of the limitation of the meteorological data in our research (the sampling quadrats was located in the same site and thus had no meteorological variation within each year), we first conducted a Pearson correlation analysis between the characteristics of aboveground vegetation, soil seed bank and meteorological factors to determine the vital meteorological variable. After that, the dominant meteorological factor was included in our SEM (Additional file 1: Fig. S2a). The growing season data was selected for use in our model, and the species richness and abundance 
of aboveground vegetation were calculated as the sum of the three life forms transformed in the same scale.

The microtopographic factors were micro-elevation, slope gradient and slope aspect of each quadrat. Because local microtopography has a greater influence on the distribution pattern of shrubs in the site which has a great influence on seed yields and reserves in deserts, we also included shrub coverage as an intermediate variable in the microtopography model (Additional file 1: Fig. $\mathrm{S} 2 \mathrm{~b})$. These two models included all possible pathways to quantify the plausible impacts of environmental and vegetative factors on the soil seed bank. The Chi-square test, the index of goodness-of-fit (GFI) and comparative fit index (CFI) were used to evaluate the fit of the model (Fan et al. 2016). Before analysis, all data was log-transformed to improve normality.

Non-metric multidimensional scaling (NMDS) analysis was applied to assess the temporal trends and the similarity of species composition between the aboveground vegetation and the soil seed bank (Clarke 1993). For species in these two groups, we calculated the relative abundance and performed the ordination for each quadrat in each year. Three life form species (shrubs, perennial herbs, annual herbs) and total species were conducted, respectively. The NMDS analysis were based on the Bray-Curtis distance as a measurement of similarity matrices, and it was found that the stress value should be smaller than $20 \%$ to reflect the species abundance data accurately (Kindt and Coe 2005). We chose this index because it is based on relative abundance data and not sensitive to variability in the total abundance and the sampling spatial scale (Kindt and Coe 2005). We used PERMANOVA tests ('anosim' function of the VEGAN R package) to test whether the community composition varies between the aboveground vegetation and the seed bank.

To clearly show the annual dynamics and the similarity of the species composition in two groups, we also performed NMDS analysis based on the relative abundance data for all the quadrats as a whole in each year. To have a direct measure of species composition similarity within the aboveground vegetation and the seed bank and between them, we measured and calculated the distance of the ordination points based on the first two axes of the NMDS results. The mean value and standard error of the ordination distance for points in NMDS were extracted for the seed bank and the aboveground vegetation, respectively, and the mean value were compared at a 0.05 significance level using a post-hoc HSD test.

All statistical analysis were conducted using the software $R$ ( $R$ version 3.6.0), and the following packages: "lavaan" for the SEM (Rosseel 2012), "vegan" for the NMDS analysis (Oksanen et al. 2019), and "ggplot2" (Wickham 2016) for plotting the figures.

\section{Results}

Properties and annual dynamics of the aboveground vegetation and seed bank

In 4-year surveys of the aboveground vegetation, 24 species were identified in 11 families. Annual herb species accounted for 12 species (50\%), perennial herbs 8 species (33\%), and shrubs 4 species (17\%) (Additional file 1: Table S1). For abundance, annual herbs accounted for the half $(50 \%)$ of the individuals, followed by perennial herbs (34\%), and shrubs (16\%). The annual mean species richness and abundance of the aboveground vegetation were relatively higher in 2012 and 2014 than in 2011 and 2013 (Fig. 1a, c).

From the seeds that germinated from the soil samples over 4 years, we identified 17 species belonging to 8 families (Additional file 1: Table S2). Of these, 8 species (47\%) were annual herb species, 6 (35\%) were perennial herbs, and $3(18 \%)$ were shrubs. Total species richness varied from 13 to 17 . Annual herbs accounted for most (75\%) of the individual germinated seeds, followed by perennial herbs (15\%), and shrubs (10\%). Artemisia scoparia, an annual herb species, comprised more than half (66\%) of the individual seeds in the soil seed bank. Overall, species richness and abundance in the seed bank differed over four measured years, but, similar to the aboveground vegetation, these metrics were relatively higher in 2012 and 2014 (Fig. 1b, d).

\section{The effects of environmental factors and aboveground vegetation on the seed bank}

The correlation analysis showed that rainfall in the growing season was the most dominant variable affecting species richness, abundance of aboveground vegetation and soil seed bank among the meteorological variables considered (with the largest correlation coefficients among all predictor variables; Table 1). However, the correlation values between soil water content, wind velocity and the composition characteristics of aboveground vegetation and soil seed bank was relatively smaller compared with rainfall. Thus, we included rainfall as the key meteorological variable in our first structural equation model $\left(X^{2}=7.318, \mathrm{DF}=2, p=0.06\right.$, $\mathrm{GFI}=0.953$, CFI $=0.916$ ) (Fig. 2a). Our results showed that rainfall in the growing season had a positive direct effect on species richness and abundance of the seed bank and also an indirect effect through its impact on the aboveground vegetation.

The second structural equation model $\left(X^{2}=9.855\right.$, $\mathrm{DF}=4, p=0.08, \mathrm{GFI}=0.958, \mathrm{CFI}=0.885)$ showed that the quadrat micro-elevation had a direct negative effect on the seed bank species richness and abundance and an indirect effect on the seed bank abundance through 

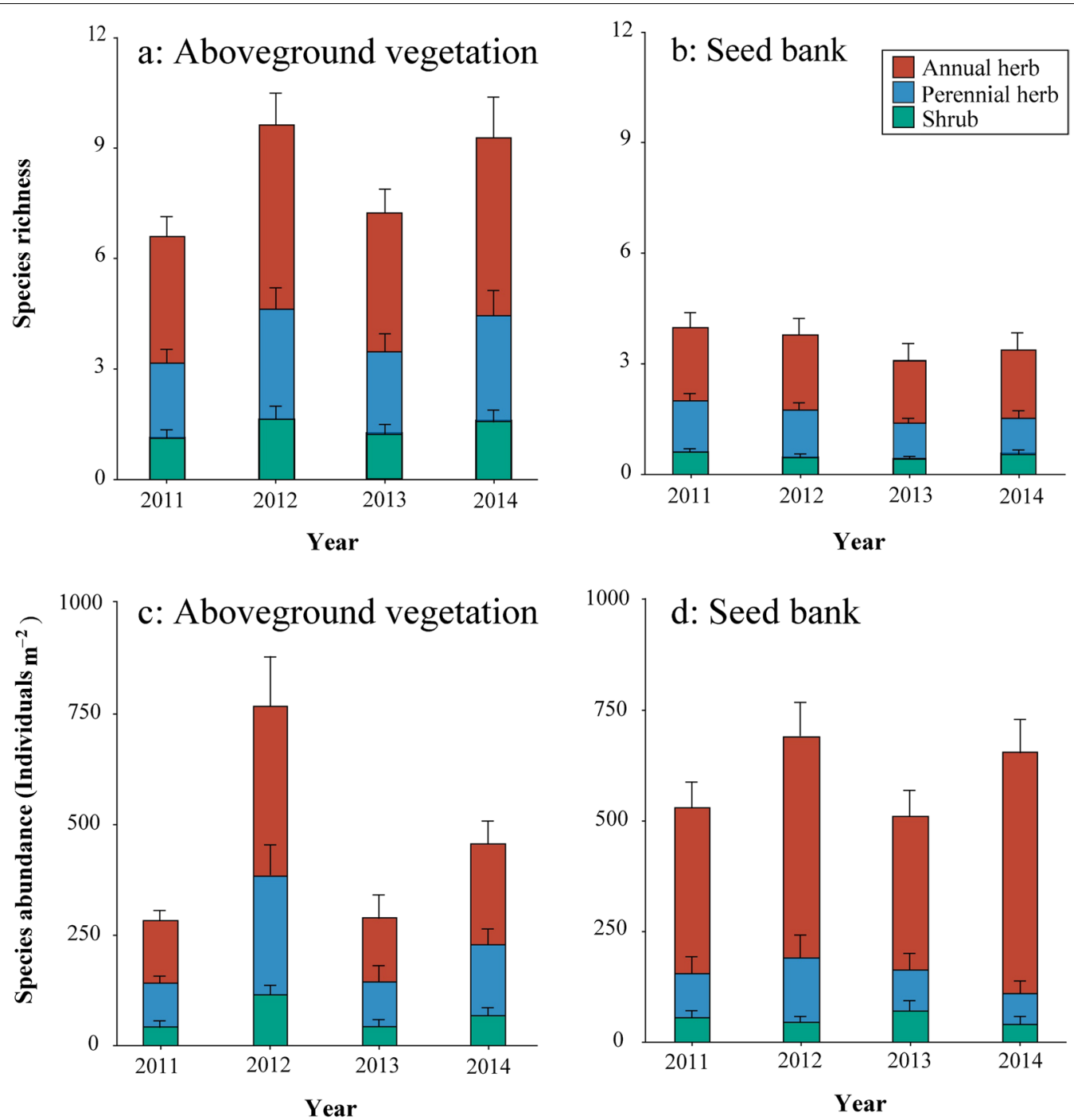

Fig. 1 Mean species richness of the aboveground vegetation $\mathbf{a}$ and soil seed bank $\mathbf{b}$ and abundance of the aboveground vegetation $\mathbf{c}$ and soil seed bank $\mathbf{d}$ per quadrat in four measured year. Values are Mean \pm Se $(n=37)$

Table 1 Pearson correlation coefficients between species richness, abundance of aboveground vegetation, soil seed bank and main meteorological factors in growing season (April to October) across all measured years

\begin{tabular}{|c|c|c|c|c|}
\hline \multirow[t]{2}{*}{ Meteorological factors } & \multicolumn{2}{|l|}{ Species richness } & \multicolumn{2}{|l|}{ Abundance } \\
\hline & Aboveground vegetation & Soil seed bank & Aboveground vegetation & Soil seed bank \\
\hline Rainfall & 0.705 & 0.531 & 0.796 & 0.790 \\
\hline Soil water & 0.536 & 0.292 & 0.552 & 0.655 \\
\hline Wind velocity & 0.101 & 0.383 & 0.590 & 0.368 \\
\hline
\end{tabular}

Bold font indicated the largest correlation coefficients for each response variable

the aboveground vegetation abundance (Fig. 2b). However, no significant paths were found leading from microtopographic factors to shrub cover and then to the seed bank.
The similarity between the seed bank and aboveground vegetation

Anosim test showed that the species composition of the seed bank and the aboveground vegetation were divided 

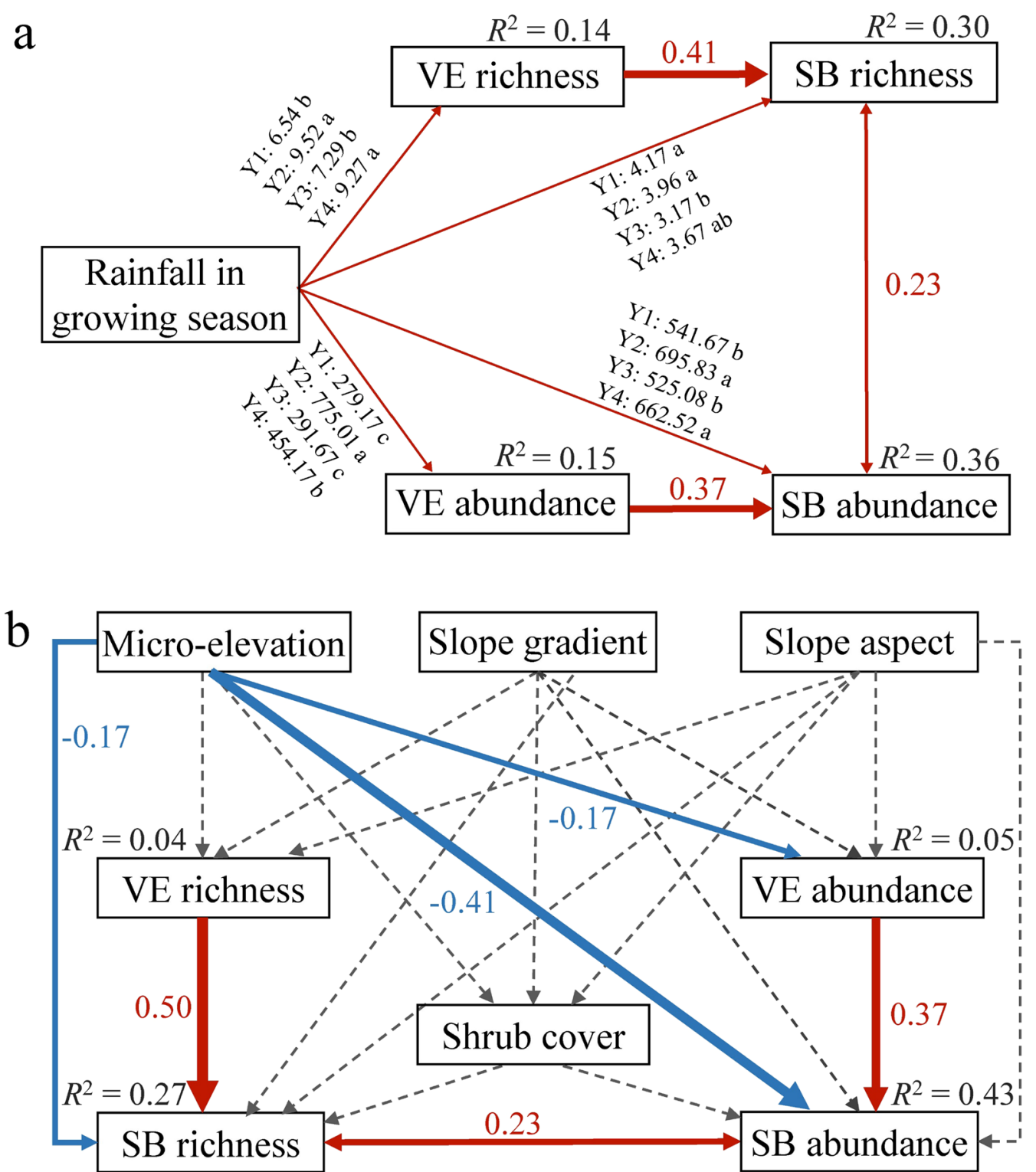

Fig. 2 a First structural equation model (SEM) linking rainfall in the growing season to species richness (VE richness) and abundance (VE abundance) of the aboveground vegetation and to species richness (SB richness) and abundance (SB abundance) of the soil seed bank in each quadrat. b Second SEM linking microtopographic conditions to species richness and abundance of aboveground vegetation, and shrub coverage to species richness and abundance of the soil seed bank. Red, blue and dotted arrows represent significant positive, negative and nonsignificant effects at 0.05 level, respectively $(n=148)$. Numbers indicate the significant standard path coefficients and the thickness of the colored arrows reflects its relative magnitude. Letters $\mathbf{a}-\mathbf{c}$ in the above figure denote groupings via post-hoc tests. Multiple $R^{2}$ is displayed at the top of each response variable

into two distinct groups in the first two axes of the NMDS for all species, shrub species and perennial herb species, respectively (Additional file 1: Fig. S3a-c). However, there is no clearly distinction between the two groups for annual herb species (Additional file 1: Fig. S3d). The ordination distance for all life form species among 4 years within the seed bank was $0.330 \pm 0.065$ (Mean \pm Se), which was significant smaller than that within aboveground vegetation $(0.861 \pm 0.112$; Fig. $3 \mathrm{a}$ and Table 2$)$. Meanwhile, the within-group ordination distance of these two groups was significantly smaller than the distance between them $(1.428 \pm 0.299)$. The results showed that the species composition of the seed bank have larger similarity than that of the aboveground vegetation. 

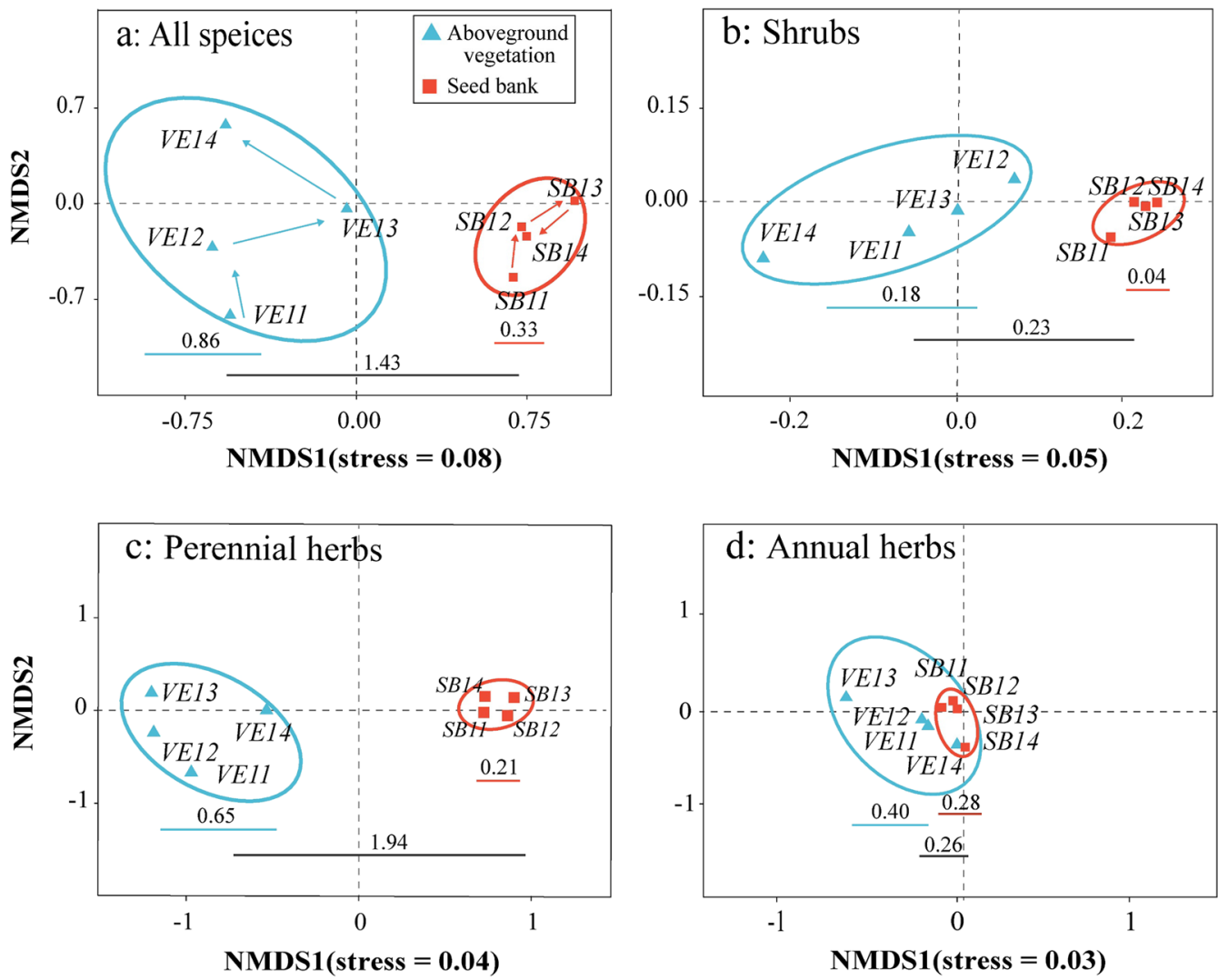

Fig. 3 NMDS ordination of the species composition of the aboveground vegetation (VE11-14) and soil seed bank (SB11-14) for all the quadrats as a whole in four measured years (2011-2014). Shown are a all species; b shrub species; c perennial herb species; d annual herb species. The location of ordination points within each diagram indicate the degree of similarity between each one in the first two axes of NMDS. Colored ellipses represent different species groups based on $85 \%$ level confidence intervals. In figure a, arrows represent the temporal change of the ordination points of the soil seed bank and aboveground vegetation. The ordination distances within the aboveground vegetation, the seed bank, and between these two groups are shown in values above the different line segments, respectively. The length of line segments represent the relative magnitude of ordination distance for each group. The detailed statistics results about the ordination distances are listed in Table 2

Table 2 Ordination distances within the aboveground vegetation, the soil seed bank and between the two groups for different life form species based on the first two axes of the two-dimensional non-metric multidimensional scaling (NMDS) ordination in Fig. 3

\begin{tabular}{llll}
\hline Life forms & \multicolumn{2}{l}{ The ordination distances (Mean \pm Se) } \\
\cline { 2 - 3 } & within the aboveground vegetation $(\boldsymbol{n}=6)$ & within the soil seed bank $(\boldsymbol{n}=\mathbf{6})$ & $\begin{array}{l}\text { between the two } \\
\text { groups }(\boldsymbol{n}=\mathbf{1 6})\end{array}$ \\
\hline All & $0.861 \pm 0.112^{\mathrm{b}}$ & $0.330 \pm 0.065^{\mathrm{c}}$ & $1.428 \pm 0.299^{\mathrm{a}}$ \\
Shrub & $0.176 \pm 0.036^{\mathrm{ab}}$ & $0.041 \pm 0.025^{\mathrm{b}}$ & $0.231 \pm 0.027^{\mathrm{a}}$ \\
Perennial herbs & $0.649 \pm 0.065^{\mathrm{b}}$ & $0.206 \pm 0.017^{\mathrm{c}}$ & $1.941 \pm 0.072^{\mathrm{a}}$ \\
Annual herbs & $0.397 \pm 0.092^{\mathrm{a}}$ & $0.279 \pm 0.072^{\mathrm{a}}$ & $0.261 \pm 0.047^{\mathrm{a}}$ \\
\hline
\end{tabular}

Within each row, different letters represent significant differences within the soil seed bank, the aboveground vegetation and between the two groups for different life form species according to a post-hoc HSD tests at $p<0.05$ level

Similar to the total species, the ordination distance of the aboveground vegetation for shrub and perennial herb species were also larger than that of the seed bank, respectively (Fig. 3b, c; Table 2). For annual herb species, however, the species composition of the soil seed bank clustered together with the aboveground vegetation (Additional file 1: Fig. S3d), and the within-group ordination distance of the two groups did not differ significantly (Table 2). Overall, these results indicated that the species composition of the seed bank samples had less 
annual change and more similarity compared with the aboveground vegetation. In addition, when considering life forms, the similarity of species composition between the aboveground vegetation and seed bank was significant lower for shrub and perennial herb species than for annual herbs.

\section{Discussion}

\section{Effect of rainfall, quadrat micro-elevation and shrub} coverage on the soil seed bank

Our first hypothesis, that rainfall in the growing season is the most critical environmental factor influencing soil seed bank, was verified. The SEM results showed that rainfall exerts both direct and indirect effects on the species composition and size of the soil seed bank. In arid regions, an increase in rainfall could promote the growth of plants, especially herbs, leading to greater seed production and a larger seed bank (Shen and Ehrenfeld 2009). On the other hand, biological soil crusts, which exist widely in deserts and maintain soil structure and moisture, could prevent these seeds from entering the soil (Li et al. 2005). Intense rainfall events, however, can break the structure of biological soil crusts and allow seeds passage into the soil (Pando-Moreno et al. 2014; Rivera-Aguilar et al. 2005). Meanwhile, the possible important effects of soil water content on soil seed bank was not proved by our result. It indicated that rainfall events could be more important than soil water content per se in determining the soil seed bank diversity and size. In addition, wind velocity had the smallest correlation with soil seed bank composition indicating that the hypothesized impacts of wind on desert soil seed bank was not verified.

The quadrat micro-elevation was negatively related to the soil seed bank, in agreement with previous findings (Gomaa 2014, 2018; Liu et al. 2016). Higher micro-elevation sites do not capture or retain seeds well because wind and gravity drive seeds downhill (Li et al. 2017). Hydrothermal differences caused by microtopography may also determine whether seeds can germinate or lie dormant in the soil (Novak et al. 2011; Thompson et al. 2003). In addition, quadrats at relatively higher microelevation are limited by lower soil moisture and nutrients and tend to have relatively poor vegetation growth, which thus leads to lower seed yields compared with lower locations (Havrdová et al. 2015).

In general, shrubs could accumulate larger seed banks by trapping seeds. In our results, however, no significant relationships were found between shrub coverage and the species richness and abundance of the seed bank. This discrepancy may be explained by the slight differences in shrub coverage over the study site, which translated into a slight difference in capturing seeds due to the changed microenvironment (Tackenberg and Stöcklin 2008). This probably also occurred because the shrubs may restrict the growth of annual herbs and thus reduce seed yields (Aguiar and Sala 1997; Ozinga et al. 2004). However, these results highlight the complexity of how both aboveground vegetation and microenvironment influence soil seed bank, and emphasize the need to further explore the combined effects of shrub coverage and microenvironment in desert ecosystems.

\section{The effect of annual herbs on the seed bank}

Consistent with our second hypothesis, we found that the synchronous changes in the soil seed bank and the aboveground vegetation mainly depended on annual herbs, which suggests a tight within-year coupling between the soil seed bank and aboveground vegetation in desert ecosystems. The relationship between the seed bank and annual herbs of aboveground vegetation clearly demonstrated that the growth of annual herbs could have a direct and immediate effect on the soil seed bank.

The seed yields of annual herbs are often much higher than of other life forms, which may rely more on vegetative reproduction (Martiniello 1999). In our study, for example, the dominant shrubs, $A$. ordosica and Caragana korshinskii and the perennial herbs Iris tenuifolia and Allium mongolicum, can all reproduce by cloning their branches and/or rhizomes (Ma et al. 2002). Further exacerbating this difference, the smaller seed size of annual herbs means that they can more easily penetrate gaps in the biological soil crusts in our study area (Li et al. 2005; Pando-Moreno et al. 2014). In addition, seeds of annual herbs usually have a shorter dormancy time than seeds of shrubs and perennials (Finch-Savage and LeubnerMetzger 2006). In our study, we used the seedling emergence method to define the soil seed bank, and the soil samples were watered frequently. Under these sufficient water conditions, annual herbs often have higher seed vigour and germinate rapidly (Jakobsson and Eriksson 2003; Novak et al. 2011). Overall, our results showed synchronous changes between the seed bank and aboveground vegetation in a desert ecosystem, and future studies should focus on elucidating how the population dynamics of individual species in the seed bank respond to changes in the aboveground vegetation of deserts.

\section{Similarity between seed bank and aboveground vegetation and variation in soil seed bank}

We found that year-to-year changes in the composition of the seed bank were smaller and thus had larger similarity within the groups than that in aboveground vegetation, which supported our third hypothesis and also mirrored similar results from other ecosystems, such as in arctic coastal marsh, alpine meadows, and other arid 
ecosystems (Chang et al. 2001; Ma et al. 2017; Zhang et al. 2016). There are several reasons for our results. First, the low species diversity of the seed bank in desert itself could directly result in its small annual change in species composition. Second, the vegetation of arid environments tends to have more taxa with dormant seeds than benign environments do (Bakker et al. 1996; Kalamees et al. 2013). Seed dormancy facilitates a sustainable and long-term seed bank in temporally and spatially unpredictable environments, such as deserts (Kleemann and Gill 2013). Seed dormancy is an adaptive trait, a way to maximize progeny number by extending seed lifetime (Facelli et al. 2005). Therefore, dormant seeds increase the stability of seed bank composition, and this persistent seed bank could, therefore, act as an important resource for restoration and management (Bakker et al. 1996; Kalamees et al. 2013).

As the constructive and dominant life form in deserts, shrubs play a decisive role in the stability of the ecosystem (Ma et al. 2002). Perennial herbs are also an important component of ecosystem resilience and resistance (Abella and Smith 2013). However, in our study, the species compositions and individual proportions of shrubs and perennial herbs in the seed bank were greatly lower than those of the aboveground plant communities. Although the species composition of the soil seed bank had less fluctuation than the aboveground plant communities in our study, the lack of shrub and perennial seeds may inhibit the regeneration of such species when considering the recovery and restoration of degraded desert ecosystems.

\section{Conclusion}

Based on a relative long-term observational study, we evaluated the effects of environmental factors and aboveground vegetation on the species composition of a desert soil seed bank. Rainfall in the growing season had a substantial positive effect on the soil seed bank richness and abundance, while quadrat micro-elevation had a negative effect on the seed bank. The synchronous changes in the soil seed bank and aboveground vegetation were mainly driven by annual herb species. The species composition of the seed bank had less year-to-year fluctuation and larger similarity than the aboveground vegetation, indicating that the seed bank may have great potential to be a source of restoration for degraded desert ecosystems. However, because of the low diversity and abundance of shrub and perennial herb seeds and the fast response of annual herb seeds to rainfall, it may be difficult to restore a degraded desert by relying solely on the seed bank and natural regeneration. Our study highlights the importance of long-term investigations of the soil seed bank and the requirement of appropriate interventions, such as artificial reseeding of shrubs and perennials, to promote the restoration of arid degraded ecosystems.

\section{Supplementary Information}

The online version contains supplementary material available at https://doi. org/10.1186/s13717-021-00346-w.

Additional file 1. Table S1. Species composition and frequency (\%) of the aboveground vegetation from 2011 to 2014. Table S2. Species composition and individual number of seeds for each species that germinated from the soil seed bank. Fig S1. Location of the study site and the sampling diagram. Fig S2. The concept model linking vital environmental factors to the aboveground vegetation and soil seed bank. Fig S3. NMDS ordination of the species composition in the aboveground vegetation and seed bank.

\section{Acknowledgements}

We would like to thank Profs. Simon Queenborough and Elizabeth Tokarz at the Yale University for their assistance with English language editing of the manuscript.

\section{Authors' contributions}

ZS Zhang and YZ designed research, YFS analyzed the data and wrote the paper; ZRW, BXX, JQH, and RH acquired and analyzed data. All authors read and approved the final manuscript.

\section{Funding}

This work was supported by the National Natural Science Foundation of China (Grant No. 3197529) and the Strategic Priority Research Program of the Chinese Academy of Sciences (XDA23060200).

Availability of data and materials

The data are available from the corresponding author on reasonable request.

\section{Declarations}

Ethics approval and consent to participate Not applicable.

Consent for publication

Not applicable.

Competing interests

The authors declare that they have no competing interests.

\section{Author details}

${ }^{1}$ Shapotou Desert Research and Experiment Station, Northwest Institute of Eco-Environment and Resources, Chinese Academy of Sciences, Lanzhou 730000, Gansu Province, People's Republic of China. ${ }^{2}$ University of Chinese Academy of Sciences, Beijing 100049, People's Republic of China. ${ }^{3}$ State Key Laboratory of Grassland Agro-Ecosystems, Key Laboratory of Grassland Livestock Industry Innovation, Ministry of Agriculture and Rural Affairs, Engineering Research Center of Grassland Industry, Ministry of Education, College of Pastoral Agriculture Science and Technology, Lanzhou University, Lanzhou 730020, Gansu Province, People's Republic of China.

Received: 14 September 2021 Accepted: 19 November 2021 Published online: 09 January 2022

\section{References}

Abella SR, Smith SD (2013) Annual-perennial plant relationships and species selection for desert restoration. J Arid Land 5:298-309. https://doi.org/10. 1007/s40333-013-0172-0

Aguiar MR, Sala OE (1997) Seed distribution constrains the dynamics of the Patagonian steppe. Ecology 78:93-100. https://doi.org/10.2307/2265981 
Arruda AJ, Buisson E, Poschlod P, Silveira FAO (2018) How have we studied seed rain in grasslands and what do we need to improve for better restoration? Restor Ecol 26:S84-S91. https://doi.org/10.1111/rec.12686

Bai YX, She WW, Zhang YQ, Qiao YG, Fu J, Qin SG (2020) N enrichment, increased precipitation, and the effect of shrubs collectively shape the plant community in a desert ecosystem in northern China. Sci Total Environ 716:135379. https://doi.org/10.1016/j.scitotenv.2019.135379

Bakker JP, Berendse F (1999) Constraints in the restoration of ecological diversity in grassland and heathland communities. Trends Ecol Evol 14:63-68. https://doi.org/10.1016/S0169-5347(98)01544-4

Bakker JP, Poschlod P, Strykstra RJ, Bekker RM, Thompson K (1996) Seed banks and seed dispersal: important topics in restoration ecology. Plant Biol 45:461-490. https://doi.org/10.1111/j.1438-8677.1996.tb00806.x

Boudell JA, Link SO, Johansen JR (2002) Effect of soil microtopography on seed bank distribution in the shrub-steppe. West North Am Naturalist 62:14-24

Brändel M, Schütz W (2005) Temperature effects on dormancy levels and germination in temperate forest sedges (Carex). Plant Ecol 176:245-261. https://doi.org/10.1007/s11258-004-0117-y

Chang ER, Jefferies RL, Carleton TJ (2001) Relationship between vegetation and soil seed banks in an arctic coastal marsh. J Ecol 89:367-384. https:// doi.org/10.1046/j.1365-2745.2001.00549.x

Chen YL, Zhang ZS, Zhao Y, Hu YG, Zhang DH (2018) Soil carbon storage along a 46-year revegetation chronosequence in a desert area of northern China. Geoderma 325:28-36. https://doi.org/10.1016/j.geoderma.2018. 03.024

Clarke KR (1993) Non-parametric multivariate analyses of changes in community structure. Austral Ecol 18:117-143. https://doi.org/10.1111/j.14429993.1993.tb00438.x

Estrada A, Meireles C, Morales-Castilla I, Poschlod P, Vieites D, Araújo MB, Early $R$ (2015) Species' intrinsic traits inform their range limitations and vulnerability under environmental change. Global Ecol Biogeogr 24:849-858. https://doi.org/10.1111/geb.12306

Facelli J, Chesson P, Barnes N (2005) Differences in seed biology of annual plants in arid lands: a key ingredient of the storage effect. Ecology 86:2998-3006. https://doi.org/10.1890/05-0304

Fan Y, Chen J, Shirkey G, John R, Wu S, Park H, Shao C (2016) Applications of structural equation modeling (SEM) in ecological studies: an updated review. Ecol Process 5:19. https://doi.org/10.1186/s13717-016-0063-3

Finch-Savage WE, Leubner-Metzger G (2006) Seed dormancy and control of germination. New Phytol 171:501-523. https://doi.org/10.1111/j.14698137.2006.01787.x

Gomaa NH (2014) Microhabitat variations and seed bank-vegetation relationships in a desert wadi ecosystem. Flora 209:725-732. https://doi.org/10. 1016/j.flora.2014.09.004

Gomaa NH (2018) Reproductive traits, flowering phenology and seed bank dynamics in Retama raetam (Fabaceae) in a hyper-arid environment. Arid Land Res Manag 33:1-21. https://doi.org/10.1080/15324982.2018.1510440

Havrdová A, Douda J, Doudová J (2015) Local topography affects seed bank successional patterns in alluvial meadows. Flora 217:155-163. https://doi. org/10.1016/j.flora.2015.10.007

Houerou H (1996) Climate change, drought and desertification. J Arid Environ 34:133-185. https://doi.org/10.1006/jare.1996.0099

Hu A, Zhang J, Chen X, Chang S, Hou F (2019) Winter grazing and rainfall synergistically affect soil seed bank in semiarid area. Rangel Ecol Manag 72:160-167. https://doi.org/10.1016/j.rama.2018.07.012

Huang Z, Footitt S, Tang A, Finch-Savage WE (2018) Predicted global warming scenarios impact on the mother plant to alter seed dormancy and germination behaviour in Arabidopsis. Plant Cell Environ 41:187-197. https:// doi.org/10.1111/pce.13082

Jacquemyn H, Van Mechelen C, Brys R, Honnay O (2011) Management effects on the vegetation and soil seed bank of calcareous grasslands: an 11-year experiment. Biol Conserv 144:416-422. https://doi.org/10.1016/j.biocon. 2010.09.020

Jaganathan GK, Dalrymple SE, Liu BL (2015) Towards an understanding of factors controlling seed bank composition and longevity in the alpine environment. Bot Rev 81:70-103. https://doi.org/10.1007/s12229-014-9150-2

Jakobsson A, Eriksson O (2003) A comparative study of seed number, seed size, seedling size and recruitment in grassland plants. Oikos 88:494-502. https://doi.org/10.1034/j.1600-0706.2000.880304.x

Kalamees R, Püssa K, Zobel K, Zobel M (2013) Restoration potential of the persistent soil seed bank in successional calcareous (alvar) grasslands in
Estonia. Appl Veg Sci 15:208-218. https://doi.org/10.1111/j.1654-109X. 2011.01169.x

Kindt R, Coe R (2005) Tree diversity analysis. A manual and software for common statistical methods for ecological and biodiversity studies. World Agroforestry Centre (ICRAF), Nairobi, Kenya

Kleemann S, Gill G (2013) Seed dormancy and seedling emergence in ripgut brome (Bromus diandrus) populations in southern Australia. Weed Sci 61:222-229. https://doi.org/10.1614/WS-D-12-00083.1

LaForgia ML, Spasojevic MJ, Case EJ, Latimer AM, Harrison SP (2018) Seed banks of native forbs, but not exotic grasses, increase during extreme drought. Ecology 99:896-903. https://doi.org/10.1002/ecy.2160

Li XR, Jia XH, Long LQ, Zerbe S (2005) Effects of biological soil crusts on seed bank, germination and establishment of two annual plant species in the Tengger Desert (N China). Plant Soil 277:375-385. https://doi.org/10. 1007/s11104-005-8162-4

Li C, Xiao B, Wang Q, Zheng R, Wu J (2017) Responses of soil seed bank and vegetation to the increasing intensity of human disturbance in a semiarid region of northern China. Sustainability 9:1837. https://doi.org/10. 3390/su9101837

Li XR, Jia RL, Zhang ZS, Zhang P, Hui R (2018) Hydrological response of biological soil crusts to global warming: a ten-year simulative study. Global Change Biol 24:4960-4971. https://doi.org/10.1111/gcb.14378

Liu YX, Yang XL, Yao YY, Zhang GL (1985) Flora of desert. Science Press, Beijing

Liu H, Xiong ZQ, Jiang XL, Liu GH, Liu WZ (2016) Heavy metal concentrations in riparian soils along the Han River, China: the importance of soil properties, topography and upland land use. Ecol Eng 97:545-552. https://doi. org/10.1016/j.ecoleng.2016.10.060

Ma FY, Li XR, Long LQ, Zhang JG (2002) Population structure and regeneration of planted Artemisia ordocisa in Shapotou. J Desert Res 22:571-575. https://doi.org/10.1088/1009-1963/11/5/313 (in Chinese)

Ma MJ, Dalling JW, Ma Z, Zhou XH (2017) Soil environmental factors drive seed density across vegetation types on the Tibetan Plateau. Plant Soil 419:349-361. https://doi.org/10.1007/s11104-017-3348-0

Ma MJ, Baskin CC, Li WJ, Zhao YP, Zhao Y, Zhao L, Chen N, Du GZ (2019) Seed banks trigger ecological resilience in subalpine meadows abandoned after arable farming on the Tibetan Plateau. Ecol Appl 29:e01959. https:// doi.org/10.1002/eap.1959

Maestre F, Quero J, Gotelli N, Escudero A, Ochoa V, Delgado-Baquerizo M, Garcia-Gomez M, Bowker M, Soliveres S, Escolar C, Garcia-Palacios P, Berdugo M, Valencia E, Gozalo B, Gallardo A, Aguilera L, Arredondo T, Blones J, Boeken B, Zaady E (2012) Plant species richness and ecosystem multifunctionality in global drylands. Science 335:214-218. https://doi. org/10.1126/science. 1215442

Martiniello (1999) Effects of irrigation and harvest management on dry-matter yield and seed yield of annual clovers grown in pure stand and in mixtures with graminaceous species in a Mediterranean environment. Grass Forage Sci 54:52-61. https://doi.org/10.1046/j.1365-2494.1999.00153.x

Montiel S, Montaña C (2003) Seed bank dynamics of the desert cactus Opuntia rastrera in two habitats from the Chihuahuan Desert. Plant Ecol 166:241-248. https://doi.org/10.1023/A:1023255314277

Nano CEM, Bowland AE, Pavey CR (2013) Factors controlling regeneration in a rare desert tree Acacia peuce: limits to soil seed bank accumulation in time and space. J Arid Environ 90:114-122. https://doi.org/10.1016/j.jarid env.2012.10.012

Novak J, Wawrosch C, Schmiderer C, Franz C, Kopp B (2011) Germination responses of Peucedanum ostruthium (Apiaceae) to genotype, light, temperature and gibberellic acid. Seed Sci Technol 39:552-558. https:// doi.org/10.15258/sst.2011.39.3.02

Oksanen J, Blanchet FG, Friendly M, Kindt R, Legendre P, McGlinn D, Minchin PR, O'Hara RB, Simpson GL, Solymos P, Stevens MHH, Szoecs E, Wagner H (2019) vegan: community ecology package. R package version 2.5-6

Ozinga WA, Bekker RM, Schaminee JHJ, Van Groenendael JM (2004) Dispersal potential in plant communities depends on environmental conditions. J Ecol 92:767-777. https://doi.org/10.1111/j.0022-0477.2004.00916.x

Pando-Moreno M, Molina-Guerra V, Jurado E, Flores J (2014) Effect of biological soil crusts on the seed germination of three plant species under laboratory conditions. Bot Sci 92:273-279. https://doi.org/10.17129/botsci.57

Qian JQ, Liu ZM, Hatier JHB, Liu B (2016) The vertical distribution of soil seed bank and its restoration implication in an active sand dune of Northeastern Inner Mongolia, China. Land Degrad Dev 27:305-315. https://doi.org/ 10.1002/ldr.2428 
Reynolds JF, Smith DM, Lambin EF, Turner BL, Mortimore M, Batterbury SP, Downing TE, Dowlatabadi H, Fernandez RJ, Herrick JE, Huber-Sannwald E, Jiang H, Leemans R, Lynam T, Maestre FT, Ayarza M, Walker B (2007) Global desertification: building a science for dryland development. Science 316:847-851. https://doi.org/10.1126/science.1131634

Rivera-Aguilar V, Godinez-Alvarez H, Manuell-Cacheux I, Rodriguez-Zaragoza $S$ (2005) Physical effects of biological soil crusts on seed germination of two desert plants under laboratory conditions. J Arid Environ 63:344-352. https://doi.org/10.1016/j.jaridenv.2005.03.012

Rosseel Y (2012) lavaan: an R package for structural equation modeling. J Stat Softw 48:1-36. https://doi.org/10.18637/jss.v048.i02

Royo AA, Ristau TE (2013) Stochastic and deterministic processes regulate spatio-temporal variation in seed bank diversity. J Veg Sci 24:724-734. https://doi.org/10.1111/jvs.12011

Shen Y, Ehrenfeld JG (2009) The effects of changes in soil moisture on nitrogen cycling in acid wetland types of the New Jersey Pinelands (USA). Soil Biol Biochem 41:2394-2405. https://doi.org/10.1016/j.soilbio.2009.06.012

Snyman HA (2013) Disturbances impact on longevity of grass seeds, semi-arid south African rangeland. Rangel Ecol Manag 66:143-156. https://doi.org/ 10.2111/REM-D-11-00145.1

Sommer S, Zucca C, Grainger A, Cherlet M, Zougmoré R, Sokona Y, Hill J, Della Peruta R, Roehrig J, Wang G (2011) Application of indicator system for monitoring and assessment of desertification from national to global scales. Land Degrad Dev 22:184-197. https://doi.org/10.1002//dr.1084

Sternberg M, Yu S (2004) Soil seed banks, habitat heterogeneity, and regeneration strategies in a Mediterranean coastal sand dune. Isr J Plant Sci 52:213-221. https://doi.org/10.1560/HWL0-7CBQ-1DD0-YUOU

Stocklin J, Fischer M (1999) Plants with longer-lived seeds have lower local extinction rates in grassland remnants 1950-1985. Oecologia 120:539543. https://doi.org/10.1007/s004420050888

Tackenberg O, Stöcklin J (2008) Wind dispersal of alpine plant species: a comparison with lowland species. J Veg Sci 19:109-118. https://doi.org/ 10.3170/2007-8-18338

Thompson K, Ceriani R, Bakker J, Bekker RM (2003) Are seed dormancy and persistence in soil related? Seed Sci Res 13:97-100. https://doi.org/10. 1079/SSR2003128

Wickham H (2016) ggplot2: elegant graphics for data analysis. Springer-Verlag, New York

Wolters M, Bakker JP (2002) Soil seed bank and driftline composition along a successional gradient on a temperate salt marsh. Appl Veg Sci 5:55-62. https://doi.org/10.1111/j.1654-109X.2002.tb00535.X

Zhang ZM, Shen R, Zhang JL, Xu Q, Luo Y, Yu QC, Zhang QX, Ou XK (2016) Comparisons of species composition between soil seed banks and aboveground plant communities in the dry-hot valley of the Yuanjiang River. Biodiversity Sci 24:431-439. https://doi.org/10.17520/biods.20152 53 (in Chinese)

\section{Publisher's Note}

Springer Nature remains neutral with regard to jurisdictional claims in published maps and institutional affiliations.

\section{Submit your manuscript to a SpringerOpen ${ }^{\circ}$ journal and benefit from:}

- Convenient online submission

- Rigorous peer review

- Open access: articles freely available online

- High visibility within the field

- Retaining the copyright to your article 